\title{
IMPACTOS DA TEATRALIDADE NAS DRAMATURGIAS DE AUTOR
}

\author{
IMPACTOS DE LA TEATRALIDAD EN LAS DRAMATURGIAS \\ DE AUTOR
}

\section{IMPACTS OF THEATRALITY IN THE AUTHOR DRAMATURGYS}

\begin{abstract}
Antonio Mello ${ }^{1}$
\section{RESUMO}

Este artigo aborda o conceito de teatralidade a partir das transformações sofridas pelo evento teatral e seus impactos nas dramaturgias de autor. Muitas das práticas pertencentes ao teatro na contemporaneidade, não mais partirão de textos dramáticos prévios, destituindo, com isto, sua supremacia. Desse modo, entrarão em atrito com alguns setores que se empenham em compreender o fenômeno teatral ainda sob a égide da ideia aristotélica de representação.

PALAVRAS-CHAVE: Teatralidade, Performatividade, Dramaturgias

\section{RESUMEN}

Este artículo aborda el concepto de teatralidad a partir de las transformaciones sufridas por el evento teatral y sus impactos en las dramaturgias de autor. Muchas de las prácticas pertenecientes al teatro en la contemporaneidad, ya no partirán de textos dramáticos previos, destituyendo con ello su supremacía. De ese modo, entrar en fricción con algunos sectores que se empeñan en comprender el fenómeno teatral aún bajo la égida de la idea aristotélica de representación.
\end{abstract}

PALAVRAS CLAVE: Teatralidad, Performatividad, Dramaturgias

\section{ABSTRACT}

This article approaches the concept of theatricality from the transformations under gone by the theatrical event and its impacts on the play-writings of the author. Many of the practices which belong to contemporary theater, will no longer depart from previous dramatic texts, there by depositing their supremacy. In this way, they will enter in to friction with some sectors that try to understand the theatrical phenomenon still under the aegis of the Aristotelian idea of representation.

KEYBOARDS: Theatrality, Performativity, Playwrittings

$$
* * *
$$

\footnotetext{
1 Ator e diretor teatral. UFMG; doutorando. antoniobm38@hotmail.com. Pesquisa em andamento a ser finalizada em fevereiro de 2020. Teatro. Mara Leal/Ernani Maletta. CAPES, PROEX - UFMG.
} 
Ensina-nos Lessing (2005) que quando se considera a nossa matriz teatral como um remonte da tradição narrativa dramática de cunho grecoromano e judaico-cristão, refletirmos, pois, sobre o termo dramaturgia é toma-lo enquanto uma noção chave da cultura e da prática teatral no ocidente, tanto do ponto de vista do palco quanto do ponto de vista da plateia. Juntamente com as noções de espetáculo e representação, a dramaturgia formou, durante séculos, uma espécie de tripé estruturante da própria natureza do teatro e das formas narrativas ficcionais dos espetáculos, refletindo uma complexa teia de referências conceituais que problematizavam procedimentos criativos distintos. Esses procedimentos até hoje estão em permanente atualização, confrontados com o tecido social de onde essas mesmas produções se originam e pelas quais são recepcionadas.

$\mathrm{Na}$ atualidade, nos deparamos com diversas montagens teatrais que reivindicam o desenvolvimento de dramaturgias próprias, sejam por meio de escrituras performativas corporais, atorais ou autobiográficas sem que, necessariamente, se atenham à composição de um personagem no sentido psicológico ou de uma lógica linear no desencadeamento de suas ações. Portanto, as discussões sobre a construção de uma dramaturgia contemporânea, se afirmam, hoje, através de um processo criativo híbrido, onde, diante dos diversos procedimentos e determinismos vivenciados pelos grupos teatrais do ocidente, a noção de autoria não se apresenta mais tão estável como era no passado. Com isto, podemos inferir que o entendimento disto a que denominamos de dramaturgia não está mais restrito ao trabalho do autor dramático como agente criativo, mas encontra-se diluído entre a técnica de composição da própria cena e a concepção performativa dos textos. Naturalmente, estes são desdobramentos que possuem sua origem histórica e estética no trabalho teatral de Meyerhold, apesar de que, por vezes, essa matriz paradigmática também possa ser atribuída às experiências de B. Brecht e ao teatro da Crueldade de Antonin Artaud.

Para Silvia Fernandes (2011), o teatro contemporâneo, assim como a dança, as artes plásticas e o cinema partilham de uma crise de identidade e 
uma indefinição de estatuto epistemológico, que se configuram especialmente por meio de um embaralhamento dos modos espetaculares e da perda dos limites fronteiriços entre os diferentes domínios artísticos. Portanto, os traços mais evidentes deste processo, se dão pela frequência com que se situam em territórios híbridos entre as diversas possibilidades de manifestação artística, além da opção por processos criativos que não privilegiam mais a supremacia do drama para a constituição de sua teatralidade. Segundo Fernandes, as noções de teatralidade e performatividade, podem funcionar como norteadores relevantes de leitura da cena e têm se revelado como referências importantes na operação teórica das experiências de caráter eminentemente cênico. Os dois conceitos contemplam, ainda, em seu escopo teórico-prático, uma infinidade de enunciadores em sua produção. Simultaneamente, além de delinearem campos de estudo bastante específicos para as artes da cena, chegam também a confundirem-se em determinadas abordagens.

De acordo com Dieguez (2011), durante longos anos a arquitetura teatral esteve alicerçada, com uma impressionante firmeza, às premissas de uma concepção dramática estruturada pelo ponto de vista aristotélico. Apenas no final do século XIX é que se começaram a produzir as desconstruções paradigmáticas, bem como as quebras sistemáticas desse corpo dramatúrgico: Jarry, Strindberg e Artaud passaram a propor com seus textos não mais a linearidade das histórias nem o psicologismo de seus personagens mas, ao contrário: passaram a propor espaços de cruzamento nos quais se podiam reconhecer os múltiplos discursos e suas variadas vozes, a desestruturação da fábula, as rupturas com a mimese e com a estética realista e uma acentuada supremacia da linguagem corporal e dos processos vivenciais em detrimento das situações de representação. Assim, o texto dramatúrgico tornou-se objeto de múltiplas ressignificações uma vez que abarcava um conjunto de práticas que iam desde as produções pictóricas, musicais e ritualísticas até as produções religiosas de cunho mágico, espiritual e oracular. Segundo a autora, esta reelaboração do termo Dramaturgia Teatral tem aberto novas possibilidades de tessitura cênica na 
medida mesmo em que deflagra perspectivas fundamentais na sua relação com os demais elementos que compõe uma cena. Textos performáticos, icônicos, cênicos, espetaculares e dramatúrgicos passam a ter, cada um deles, a partir de então, um modo específico de operacionalizar a sua conexão com os atores. Esse novo jeito de se conceber o fato teatral como expressão artística derivada do estilhaçamento do texto dramático, incidiu diretamente no processo criativo, especialmente dos atores que já não serviam mais como intérpretes de uma personagem, mas, sim, como criadores-performers de uma espécie de entidade ficcional atravessada, muitas vezes, por sua própria história, abrindo, deste modo, o campo da cena para novas teatralidades.

Para que possamos compreender as transformações semânticas do conceito de teatralidade e de seus desdobramentos, tanto no campo da cena propriamente dito, quanto na elaboração dramatúrgica dos textos teatrais, penso que seria importante mapear algumas noções sobre o termo, tratadas por alguns autores.

Joly e Plana (2012) em O Léxico do Drama Moderno e Contemporâneo, ressaltam que o termo teatralidade é formado a partir do adjetivo teatral, associado à ideia de que o teatro deve ser tomado enquanto um objeto de especificidades concretas, sem contradições internas, evidenciando por exclusão, tudo o que está fora desse conjunto traçado, ou seja, tudo o que não é teatral em si. Assim, a teatralidade torna-se "uma generalização universalizante, dotada de uma genealogia na história da arte e das ideias (2012, p. 178)". Já o sufixo idade, nos remete ao objeto como sendo definido por sua finalidade externa, o que seria o mesmo que pensar: é teatral apenas o que deve, irrestritamente, ser teatro.

Entretanto, esse desejo-falta de teatro que um autor exprime ou que um encenador projeta num texto, encontra sua origem na linguagem, na fala que faz ouvir o ator. Seja ou não escrita ou concebida para o (ou no) palco, ela já detém uma teatralidade (Joly \& Plana, 2012, p. 180).

Patrice Pavis (2011), por sua vez,em seu Dicionário de Teatro, ressalta que a teatralidade seria tudo aquilo que, na representação ou no texto dramático, é especificamente teatral e que uma das maneiras para se 
compreender a teatralidade seria a partir ou de um sentido barthesiano ou de um sentido artaudiano:

Que é teatralidade? É o teatro menos o texto, é uma espessura de signos e de sensações que se edifica em cena a partir do argumento escrito, é aquela espécie de percepção ecumênica dos artifícios sensuais, gestos, tons, distâncias, substâncias, luzes, que submerge o texto sob a plenitude de sua linguagem exterior" (BARTHES, 1964: 41-42). Do mesmo modo, no sentido artaudiano, a teatralidade se opõe à literatura, ao teatro de texto, aos meios escritos, aos diálogos e até mesmo, às vezes, à narratividade e à "dramaticidade" de uma fábula logicamente construída (PAVIS, 1996, p. 372).

Pavis distingue ainda a ideia do especificamente teatral a partir de análises de práticas cênicas apresentadas no Festival de Avignon de 1998, provando que é perfeitamente possível desligar o termo de suas qualidades abstratas ou generalistas para trabalhá-lo com base no pragmatismo de certos procedimentos cênicos. Defende ainda que, para o espectador contemporâneo, a teatralidade se configura como um termo polissêmico, que inclui a performatividade e depende da sua leitura para se constituir, abrindo, com isto, múltiplas possibilidades de apreensão e de observação do mundo. Aqui, talvez fosse necessário distinguir os termos performatividade e performance. De acordo com Ramos (2013), de fato, há certa confusão referente à compreensão dessas duas noções, na medida em que, pensar o performativo como meramente afeito à performance é um hábito frequente. Portanto, faz-se relevante salientar que o aspecto performativo poderá estar presente em qualquer fenômeno espetacular e suas variações ocorrerão a cada caso e estarão associadas a índices mínimos e máximos de performatividade. Na situação dramática mais convencional, porexemplo, os elementos performativos estarão presentes na atuação dos atores, mas, ao mesmo tempo, ocultos sob a capa da caracterização. Já na performance art, em que já não haveria supostamente nenhuma ficção, a performatividade aparecerá nitidamente, sem quaisquer disfarces.

Em relação ao assunto Teatralidade, Josette Féral (2004) a abordará a partir da compreensão de que a mesma deve ser definida por suas capacidades de transformação, de transgressão do cotidiano, de representação e de semiotização do corpo e do sujeito para que, só assim, os territórios de ficção possam ser criados. Féral abre, com isto, uma 
perspectiva de se pensar a teatralidade atrelada às leiturasde signos, que, grosso modo, consistiriam na representação de uma cadeia de significados e sentidos, abrangendo as linguagens verbais e não-verbais. $\mathrm{O}$ ator, seu corpo, seus movimentos e sua simples presença, passarão, agora, a se configurarem como espécies de plataformas de expressividade, pelas quais o espectador atribuirá algum significado e algum sentido. Portanto, ela ressalta que "a condição da teatralidade seria, pois, a identificação (quando ela foi querida pelo outro) ou a criação (quando o sujeito a projeta sobre as coisas) de um espaço outro que o do cotidiano, um espaço que cria o olhar do espectador"(Feral, 1988, p.6).Dentro dessa concepção, pode-se inferir que a teatralidade pode ser tomada enquanto o resultado de uma dinâmica perceptiva: a do olhar que se interliga a um olhado.

Já Jorge Dubatti (2003) propõe a redefinição do vocábulo teatralidadea partir da identificação, descrição e análise das suas estruturas convivais. Isso se equivaleria dizer que para Dubatti, interessa o ato capaz de convocar o encontro de presenças, reunião ou convívio sem o qual não seria possível o evento teatral. Seu ponto de partida, segundo Ileana Dieguez (2011), foi paulatinamente sendo construído a partir de seus estudos sobre Florence Dupont e sobre as práticas orais na cultura grecoromana, sobretudo, com base em $O$ Banquete de Platão. Para Dubatti, a oralidade então presente na obra platônica, seria, em si, um fenômeno aglutinador imerso nas relações de convívio, uma vez que a transmissão dos textos por meio das narrativas, implicaria na presença de outros ouvintes, num determinado espaço, afetando e deixando-se afetarem, estimulando com isto, os vínculos sociais.

Uma dimensão política da teatralidade parece se afirmar nas postulações de Diana Taylor (2002), quando a autora realça que seus mecanismos de manifestação funcionam no intuito de serem construídos por pessoas afeitas a alcançarem um resultado cênico sem que, no entanto, todos os seus elementos precisem de serem vistos e explicitados. Para Taylor, a teatralidade abarca essa possibilidade de fazer o invisível tornar-se visível, e vice-versa, dando a ver o que possa estar por detrás dos discursos cênicos. 
O que se verifica por meio destas múltiplas definições emitidas por seus respectivos autores acerca da teatralidade, é uma disparidade de impressões que acabam por realçar a complexidade do termo, no que ele possa revelar de controverso na sua capacidade de abranger e extrapolar suas relações com a produção de conhecimento. Penso que ao se emitir essa noção, uma primeira questão que se coloca para todos é: ao se falar em teatralidade, na realidade, do que estamos falando? Ela estaria associada a que tipo de teatro? $\mathrm{Na}$ atualidade, a partir de uma certa 'desficcionalização' tão característica e tão presente na cena contemporânea, como poderíamos, á, localizar a teatralidade? Nesta espécie de inversão proporcionada por muitas estéticas, cuja principal preocupação seria a de 'abolir o teatro' em nome de escrituras performativas marcadas pela relativização da personagem em direção ao enaltecimento do eu e à irrupção do real, poderíamos pensar que a teatralidade, nesses casos, se daria em negativo, por meio de um apagamento do teatro e, por conseguinte, de uma 'não teatralidade'? Através da elaboração de Leite (2017):

Com a apresentação do real - em vez da usual representação - busca-se criar margem para eclosões de novos sentidos. Sentidos que não se apresentam somente no campo da leitura da obra, mas na sua vivência, já que muitas vezes se trata de trabalhos que pressupõem um encontro de materialidades envolvendo espaços e corpos desprotegidos do aparato teatral clássico oferecido pelo palco - com cena e plateia bem divididos - e pelas personagens (LEITE, 2017, p.49).

O primeiro a definir alguns conceitos sobre a maneira de 'como' se escrever teatro foi Aristóteles (1992) em seu livro Poética, cuja concepção da arte dramatúrgica estava, necessariamente, veiculada à ideia de mimese, ou seja, à ideia de imitação da realidade e da condição humana. Essa regra foi absorvida pela comunidade teatral do ocidente e se fez vigorar durante séculos afora. Para Aristóteles, a obra devia conter um conflito através do qual as cenas pudessem se encadear de acordo com uma ordem lógica, psicológica e cronológica, uma vez que a natureza, segundo seu pensamento, seguia numa progressão evolutiva e linear. Com toda uma argumentação teórica sem precedentes, Brecht questionou essa estrutura aristotélica para propor de maneira sistemática uma imitação dos mecanismos reguladores 
das relações sociais. Com isto, sua épica propõe uma multiplicidade de tempos e espaços que narram histórias de seres humanos em constante processo de transformação e não possuem nenhuma ordem cronologicamente linear. Para Brecht, mais importante do que girar em torno de um conflito, é se ater ao movimento das relações humanas que conduza as situações presentes na obra. Isto é o que, de fato, lhe interessa enquanto dramaturgo. A incorporação desses elementos, até então estranhos à constituição do drama, advém, sobretudo, da emersão do elemento épico nas formas dramáticas. Esta épica apresenta-se, na dramaturgia, primordialmente como um problema temporal: o drama que, até então, era inteiramente presença e presente passa, estruturalmente, a incorporar o passado, que extrapola o espaço e o tempo do palco. Esse passado é caracterizado como o passado do romance e é considerado por Peter Szondi como um dos principais responsáveis pela crise do drama moderno, na medida mesmo em que faz ruir suas formas consolidadas para configurar, assim como no romance, a contingência do mundo. Em seu texto Do livro para o palco: formas de interação entre o épico literário e o teatral, o diretor Luiz Arthur Nunes (2000) ressalta que a fala autoral ou o enunciado narrativo é, em um espetáculo, geralmente confiado ao ator e essa modalidade de narração resgata uma categoria de comunicação milenar, que lhe permite sair fora do campo ficcional proposto pela peça para poder conta-lo, descrevê-lo ou comentá-lo. No entanto, quando se começa a forjar a avassaladora imposição do ilusionismo como um dogma da arte dramática, o teatro brechtiano, ao falar diretamente para a plateia, quebrando, com isto, a quarta parede da representação realista, passa a ser uma prática condenável, na medida mesmo em que faz vacilar todo o ideal do espaço da imaginação, da teatralidade, da verossimilhança, da realidade plasmada e da ilusão perfeita. De acordo com Nunes, por conta disto, a narratividade e a atuação épicas foram, durante um longo espaço de tempo, banidas da cena consagrada pela cultura oficial.

Mas afinal, na artesania dramatúrgica de autor ou na literária,que importa quem fala? Quem fala? O que se fala e como? Que espaço e que 
forma tem a narratividade na velocidade do mundo contemporâneo? $\mathrm{Na}$ internet, por exemplo, cada indivíduo pode assumir várias identificações ao mesmo tempo podendo ser autores, editores, leitores, tradutores - de modo que os papéis se embaralham, distanciando-se de suas características tradicionais e colocando em questão a reorganização desses temas. A obra intelectual e artística compartilhada nas redes virtuais não mais se apresentam como obras duradouras e íntegras, criadas por autores que se podem identificar ou até mesmo reconhecer, mas, pelo contrário, transformam-se em produções coletivas, múltiplas e, frequentemente, anônimas. Quais os efeitos disto sobre os textos dramatúrgicos e as narrativas contemporâneas? Que impactos essa nova forma de produção teria sobre a cena teatral? Por que, ainda hoje, se narram historias uma vez que a sensação é a de que tudo, de alguma forma, na atualidade já foi abordado, visto e revisto? Ao narrarmos a vida, a existência - esse campo humano do sensível -,no teatro ou fora dele, ou ainda que virtualmente,talvez o façamos para que não sejam esquecidas, para que não nos esqueçamos de nós, do outro, do mundo. Narramos ainda, talvez, pelo simples fato de que algo possa ter nos afetado e, uma vez que nos deixamos afetar pelas pessoas, pelos encontros ou acontecimentos, muito destas experiências históricas pedem recordação. É através das narrativas, muitas delas incrementadas pela memória, sejam elas vinculadas ao universo real ou ao virtual, que partilhamos o mundo com o outro e são através destes compartilhamentos intersubjetivos que os laços sociais também deveriam se estabelecer.

Se para Walter Benjamin, a Primeira Guerra foi o derradeiro golpe nessa experiência narrativa, cuja nefasta consequência se manifestou no silêncio traumático de seus soldados impedindo-os de dar continuidade a essa experiência convival, com o advento da Segunda Guerra Mundial, muitos autores, dentre eles, Samuel Beckett, propuseram uma pulverização do sentido discursivo marcando, assim, um importante acontecimento de renovação e ruptura com as escritas dramáticas oficiais, questionando incisivamente a noção da cena cartesiana. No entanto, por mais que 
possamos nos perguntar sobre as intenções e os significados imediatos de muitas dessas escritas, isto não nega, necessariamente, a importância dos eventos pelas quais podiam estar atreladas, bem como a relevância histórica de suas propostas estéticas. Penso quepara que um texto se transforme em matéria viva, dinamizadora de um processo genuíno de expressão teatral, faz-se necessário encontrar as incontáveis possibilidades cênicas de sua essência. Trata-se, aqui, no meu entender, de se transgredir criativamente o monumento textual para que a proposta cênica possa efetivamente também se fazer polissêmica, transformando-se ora em ação, ora em debate, incrementados pela provocação e pelo questionamento. Sobre isto, de Beckett ainda se escuta:

A confusão não é invenção minha. É impossível escutar uma conversa durante cinco minutos sem perceber essa confusão. Ela nos rodeia por todas as partes, em todos os lugares e o melhor que temos a fazer é aceita-la. A única possibilidade de renovação é quando abrimos os olhos e identificamos o caos. Isto não é uma coisa que se possa compreender. (...) Como se pode admitir o caos, se o caos é o que parece ser o oposto da forma e, portanto, o destruidor daquele ideal que a arte sempre perseguiu? Mas não podemos mais evitar aceita-lo, pois chegamos a um ponto em que a nossa própria experiência é continuamente afetada pelo caos. (...)Encontrar agora uma forma que acolha a confusão é o trabalho do artista (BECKETT, 1990, p.11-12).

Talvez possamos considerar ainda, que uma das grandes questões atreladas ao estranhamento gerado pelo legado beckettiano relaciona-se justamente a essa espécie de estética do caos; ao fato de que, por sermos sujeitos atravessados indelevelmente pelo campo da linguagem, ao lidarmos com uma obra que, de maneira radical, fissura seus signos e assassina o seu sentido, ressuscitando-o a partir de novos termos, esta mesma escritura acaba por convocar o leitor/espectador a se deparar, também,com os seus próprios limites. E uma vez diante desses atritos, novas constelações deverão ser recebidas pela seara do entendimento para que, assim, outras possibilidades de invenção e fruição artísticas se façam emergentes. Essa é aponta de uma das importantes discussões presentes no livro $O$ teatro é necessário?de Denis Guénoun (2004) onde, nele, o autorse debruça sobre a história do teatro e sobre a crise da representação, acompanhando as transformações do conceito de personagem e seus impactos tanto no ator quanto no espectador. 
Em seu artigo Objeção ao retorno: é possivel escrever depois do fim da crise do drama?, Guénoun (2000) destaca que o seu processo crítico alcançou um ponto extremo nos anos 50 e 60, com maior radicalidade em Beckett, impondo a questão que perdura até os dias atuais: como escrever depois dele? Será que é preciso escrever personagens hoje? Ou será que agora só se escrevem partituras para atores, roteiros verbais para corpos em constante treinamento? Seria plausível atestar que a escrita teatral contemporânea lida basicamente com a desficcionalização da dramaturgia atoral? Teatro não representativo: eis aí o grande herdeiro da crise da representação?

Nós não vamos mais ao teatro ver personagens, nem mesmo um drama: nós vamos ver um espetáculo. Assim se organiza nossa experiência teatral. Ainda se produzem, claro, efeitos de identificação, passageiros, fugidios, como uma espécie de espuma da representação. Formam-se identificações menores, por fragmentos: fios, franjas, vestígios de uma experiência antiga que retorna aqui e ali. E também maciçamente e em outros pontos, outras identificações mais nodais, que atravessam o teatro e todo resto. Mas o teatro não pode mais se pensar tendo a categoria da identificação com o personagem como ponto determinante de análise (GUÈNOUN, 2004, p.98).

A luta contra o textocentrismo ganha um novo ingrediente com as práticas desenvolvidas por Jerzy Grotowski junto a seus atores onde, nelas, as palavras passam pelo exercício criativo podendo agora serem balbuciadas, omitidas ou até mesmo recortadas. Já não se trata mais de reproduzir uma realidade proposta pelo texto e nem de executar no palco um desenho criado pelo encenador. A figura do ator seria a do criador de movimentos e de partituras de ações corporais atreladas às suas respectivas gramáticas. Ele, junto à sua coletividade, agora participaria da construção efetiva das dramaturgias e, a partir de então, não seria difícil imaginar uma nova prática que excluiria a necessidade de se recorrer a um texto prévio.

Em seu texto Autoralidade, grupo e encenação, Rosyane Trotta (2006)afirma que, de agora em diante, com a autoria cênica passando a ganhar essa nova estrutura de funcionamento, a função do diretor permanecerá primordial - tanto para as referências dos princípios estéticos e ideológicos, quanto para a própria concepção da cena. A partir de então, a área da sala de ensaio converter-se-á em tela vazia, espaço em branco onde se farão os esboços, as rasuras e a elaboração de um vocabulário que 
abranja, a um só tempo, ação e palavra. Para Trotta, nessa configuração, quanto menor for a afinidade e a experiência entre os membros de um grupo, maior a necessidade de centralização do processo na figura de um diretor, respaldado pela apresentação de uma dramaturgia prévia. Já o processo colaborativo seria uma modalidade que procuraria conjugar, ao mesmo tempo, individualidade e pluralidade e sua principal utopia estaria expressa no papel preponderante conferido ao diálogo entre os sujeitos, na tentativa de se exercitar o consenso. Não será por acaso, talvez, penso eu, que o processo de criação que conjuga texto e cena, hoje disseminado entre os mais diversos agrupamentos teatrais, se baseie, cada vez com maior frequência, no conceito de performance, uma vez que o performer individualiza, ao mesmo tempo em que sintetiza em si próprio, a sua criação. O performer é, em muitos casos, simultaneamente autor - ator - encenador tornando-se, ele mesmo, o próprio espetáculo.

Guiado pelo princípio básico do more isless, menos é mais, o dramaturgo espanhol José Sanchis Sinisterra tem, com certa frequência, atrelado seu pensamento ao 'como' se conta em detrimento ao 'o quê' se conta. Utilizando-se de elementos da análise literária para investigar o 'como' se conta e através desta investigação buscar as correlações possíveis com as práticas cênicas, Sinisterra aposta em uma escrita e encenação centradas, primeiramente, no ator como criador e, depois, na imprevisibilidade criativa no trabalho de dramaturgos. Como esclarece-nos a atriz e jornalista venezuelana Karel Mena (1996), essa perspectiva contempla a teoria de que a história fabular e seus argumentos não se fazem mais tão importantes, uma vez que não constituem a essência da teatralidade dos textos narrativos.

\footnotetext{
Em meus seminários de escrita dramática, meus exercícios insistem muito neste destino atoral dos textos. Ao mesmo tempo, quando dirijo, minha preocupação fundamental é como dar ferramentas ao ator para que este seja um criador. Ser um criador, desde o ponto de vista atoral, quer dizer, de certo modo, ter também uma consciência dramatúrgica. Esta consciência é o pré-requisito para que o ator não seja só um intérprete. $\mathrm{O}$ ator deve ser consciente não somente daquilo que a palavra diz, mas também do espaço, do tempo, dos diferentes modos de interação, etc (...).Para mim, há um permanente trânsito entre o que é propriamente dramatúrgico e o que é propriamente atoral. Dentro deste conceito do ator como criador, não como intérprete, e do autor como escritor, mas escritor de textos para serem atuados, não para serem montados em um sentido maximalista da
} 
encenação, fui explorando por campos muito diferentes(...). Em um laboratório de criação em Barcelona lancei a pergunta provocativa de que se o teatro está condenado à figuração. $O$ teatro está condenado à figuração, a ser uma mera mímesis da realidade? Quais são as possibilidades de romper com este imperialismo mimético? Então, comecei a estudar o minimalismo na música, nas artes plásticas, na dança e inventei exercícios que são de estrutura repetitiva: gestos mínimos, actemas, como eu os chamo, e que em sua evolução produzem um tipo de teatralidade absolutamente insólita, ainda por ser explorada. Estou também introduzindo as estruturas repetitivas paulatinamente em meus trabalhos de encenação. É um campo muito amplo, há implicações filosóficas, estéticas, dramatúrgicas, etc. Considero que o texto dramático é uma partitura da cena, e o responsável por que esta partitura não seja simplesmente uma execução, e,sim, um ato de criação, é o ator (SINISTERRA, 2005, Travessias, Ed. 05, UNIOESTE, PR.).

Numa perspectiva semelhante à de Sinisterra, Gabriel Weiz (2009) em seu texto La Despersonificación, propõe o teatro pessoal - terminologia forjada por ele - que se difere do teatro de personagens, na medida mesmo em que o ator é convocado a construir, sobre sua identidade, conflitos alheios à sua própria constituição interna. Isso quer dizer que em torno do teatro pessoal, gravita uma dramaturgia viva gerada pela pessoa do ator, por seu ser enquanto indivíduo colocado em contraste com o teatro de personagens, que, por sua vez, demandaria a figuração de condutas propostas por um texto dramático prévio. Assim sendo, enquanto o teatro de personagens se cria a partir de uma ficção e de um pacto tácito de ilusão estabelecido entre ator e espectador, o teatro pessoal se impõe enquanto uma irrupção do real no território poético da expressividade artística, onde não haveria um compromisso prévio nem com a realidade, muito menos com um sentido aparente proposto pelo discurso performativo. Seria, então, o ator, neste caso, um improvisador, um poeta involuntário do espaço à mercê das improbabilidades e inconstâncias casuais, que atravessariam a sua relação com a plateia? Porque, de fato, a partir de então, esses dois campos cênicos o da improvisação e o do teatro pessoal, parecem criar algumas zonas de convergência e aproximação entre ambos.

Renzo Casali (1996) nos alerta sobre esse território do improviso, afirmando que com alma, intuição de poeta e a ação de improvisar, o ator decide, de maneira radical, pertencer à situação proposta agora regulada por uma nova lógica de sentidos e, por conseguinte, de fruição, decorrentes da erupção das contingências no interior de sua própria cena. A substância 
principal do seu ato repentino, deixa de ser essa unidade pertencente ao pensamento cartesiano, cujo objetivo maior é o da representação, e passa a se configurar como um novo vocabulário cênico. Nesse sentido, talvez, possamos inferir que os atores de improvisação, assim como os atores adeptos do teatro pessoal e atoral, não mais representam um outro, mas, sim, se fazem presença de si mesmos. Trata-se, aqui, como nos ensina José Sanchis Sinisterra em entrevista realizada por Rine Leal (1996), de se explorar uma poética que possibilite uma abertura para os espaços da teatralidade, bem como para as suas dimensões de ambiguidade e de polissemia, questionando as maneiras pelas quais os discursos e suas significações se constroem. A partir dessa convocação do ator a ocupar uma posição de criador e, não mais, de mero intérprete, é necessário, agora, lidar com a possibilidade da elaboração de um texto criativo que se desvele a partir de sua bagagem pessoal e potencial relacionada à sua subjetividade. Com base nesta assertiva, penso que ao optarmos por percorrer este caminho caracterizado pelo entrelaçamento entre vida real e obra ficcional, talvez, não devamos associar a centelha criativa somente ao universo da arte, uma vez que possivelmente percamos, com isto, a dimensão das criações cotidianas e da sua capacidade de fazer nascer novas perguntas para se enfrentar os conflitos diários. Desta feita, a criatividade talvez não seja tão somente um monopólio da arte, mas, antes, faz-se como um exercício real do ser humano em sua relação com o mundo. Isto, fatalmente, incidirá na qualidade artística e porque não dizer, performativa, de alguém que se pretenda enveredar por este universo. No que diz respeito aos grupos de teatro e, mais especificamente, aos grupos latino-americanos, na atualidade, esta ebulição da criatividade caracteriza importantes momentos de busca de suas próprias vozes, do diálogo e de sua apropriação de espaços dentro das comunidades, através das quais se efetivam novas propostas de atuação, mobilização e resistência. Pela criatividade, também se arregimenta no interior da formação desses grupos a função primordial de se rever as velhas respostas para novos problemas.Através do interesse de seus membros pela autorreflexão, pelas insignificâncias da vida, pela complexidade humana e 
pelos lugares que ocupam nas relações com o outro, é que a excelência do ato criativo, bem como do aprendizado e amadurecimento pessoais, também se dará. A experiência de se criar, de sensibilizar-se frente a sua realidade e a alheia, imaginando caminhos e alternativas para melhorar sua qualidade estrutural, é um exercício democrático e de responsabilidade artísticopolítico-social das mais relevantes.

Para finalizar, cabe ressaltar que a contaminação entre teatralidade e performatividade nos processos de criação, bem como seus desdobramentos sobre as dramaturgias textuais, se faz cada vez mais evidente nos trabalhos apresentados por muitos doscoletivos contemporâneos de teatro. Seus processos colaborativos evidenciam a hibridização cada vez mais recorrente entre essas duas concepções relacionadas às artes da cena, deixando, muitas vezes, a impressão de que não é possível separar o espetáculo, supostamente acabado, do processo que nele permanece como resíduo aberto. Numa dimensão performativa acentuada por essa indistinção entre o que é montagem e o que dela escapa; entre o que é real e o que não; a partir desses deslizamentos de um território a outro, talvez, o que se crie seja um fluxo de transito contínuo entre as funções dos criadores e dos espectadores. Nesse sentido, pode-se deduzir que a nova função do espectador, talvez, esteja em pé de igualdade com o lugar de uma testemunha privilegiada, diante de uma dramaturgia cênica que também registra e revela seu processo inacabado de montagem. Mas isso é uma outra história a ser explorada em uma nova pesquisa.

$$
* * *
$$

\section{REFERÊNCIAS}

ARISTÓTELES. Poética. Trad. Eudoro de Souza. São Paulo: ARS Poética, 1992.

BECKETT, Samuel. Entrevista a Tom Driver. In: Primer Acto, n. 233, 1990. 
CASALI, Renzo. No anticipar la historia. In: MUGUERCIA, Magaly (Org.) Pedagogía y Experimentación en el Teatro Latinoamericano. México: Escenología, p. 419-436, 1996.

DIEGUEZ, Ileana. Cenários Liminares: teatralidade e performance política. Uberlândia. Ed: Edufu, 2011.

DUBATTI, Jorge. El convivio teatral. Teoría y practicadel Teatro Comparado. Buenos Ayres: Atuel, 2003.

FÉRAL, Josette. El Interculturalismo y los problemas de recepción. In: FÉRAL, Josette. Teatro, teoría y práctica: más allá de las fronteras, Buenos Aires: Galerna, 2004.

FÉRAL, Josette. Por uma poética da performatividade: o teatro performativo. Trad. Lígia Borges. In:Revista Sala Preta, São Paulo, n. 8, p. 197-210, 2008.

FÉRAL, Josette. A teatralidade. Trad. Francine Roche. In: Poétique, Revue de Théorie et dánalyse littéraires, Ed. Seuil, número 75, setembro, 1988.

FERNANDES, Silvia. Teatralidade e Performatividade na Cena Contemporânea. In: Repertório, Salvador, nº 16, p.11-23, 2011.

GUÉNOUN, Denis. Objeção ao retorno: é possível escrever depois do fim da crise do drama?. In: Folhetim, n ${ }^{\circ}$ 8. Teatro pequeno gesto. Set-dez 2000.

GUÈnOUN, Denis. O Teatro é necessário?, Perspectiva, São Paulo, 2004, p.98.

JOLLY, Geneviève; PLANA, Muriel. Teatralidade. In: SARRAZAC, Jeanpierre (Org.) Léxico do drama moderno e contemporâneo. São Paulo, Cosac Naify, 2012. p. 178-181.

LEAL, Rina. La práctica teatral necessita um pensamento científico. In: MUGUERCIA, Magaly (Org.) Pedagogía y Experimentación en el Teatro Latinoamericano. México: Escenología, p. 399-417, 1996.

LEITE, Janaína. Auto Escrituras Performativas: do Diário à Cena. São Paulo, Perspectiva, Fapesp, 2017.

LESSING, Gotthold Ephraim. Dramaturgia de Hamburgo. Trad, introd e notas de NUNES, Manuela. Lisboa, Fundação Calouste Gulbenkian, 2005. 
MENA, Karel. "Cruzar" lasfronteras: de la narrativa al teatro. In: MUGUERCIA, Magaly (Org.) Pedagogía y Experimentación en el Teatro Latinoamericano. México: Escenología, 1996, p. 245-258.

NUNES, Luiz Arthur. Do livro para o palco: formas de interação entre o épico literário e o teatral. In: O Percevejo, n 9, Ano 8. Rio de Janeiro, 2000.

PAVIS, Patrice. Dicionário de Teatro. São Paulo: Perspectiva, 2011.

RAMOS, Luiz Fernando. O conceito de performativo, a performance e o desempenho espetacular. In: Rebento - Revista de Artes do Espetáculo, $\mathrm{n}^{\mathrm{o}} 4,2013$.

SINISTERRA, José Sanchis. Dramaturgia Atoral. In: Revista Travessias, Ed. 05, UNIOESTE, Paraná, 2005.

TAYLOR, Diana. Encenando a memória social: Yuyachkani. In: RAVETTI, Graciela; ARBEX, Márcia (Org.). Performance, exílio, fronteiras: errâncias territoriais e textuais. Trad. Leda Martins. Belo Horizonte: Faculdade de Letras da UFMG, 2002. p. 13-45.

TROTTA, Rosyane. Autoralidade, grupo e encenação. In: Sala Preta, São Paulo, 2006.

WEISZ, Gabriel. La Despersonificación. In: DIÉGUEZ, Ileana (org.). Des/Tejiendo Escenas. Desmontajes: procesos de investigación y creación. Cidade do México: Universidade Ibero-americana, 2009, p. 93103.

Recebido em março de 2019.

Aprovado em abril de 2019.

Publicado em junho de 2019. 